\title{
Characterization of amino acid residues of T-cell receptors interacting with HLA-A*02-restricted antigen peptides
}

\author{
Ying Zhu ${ }^{1 \#}$, Changxin Huang ${ }^{2 \#}$, Meng $\mathrm{Su}^{3}$, Zuanmin $\mathrm{Ge}^{4}$, Lanlan Gao ${ }^{4}$, Yanfei Shi ${ }^{4}$, Xuechun Wang ${ }^{3}$, \\ Jianfeng Chen ${ }^{5}$ \\ ${ }^{1}$ Department of Oncology, First Affiliated Hospital of Zhejiang Chinese Medical University, Hangzhou, China; ${ }^{2}$ Department of Oncology, Affiliated \\ Hospital of Hangzhou Normal University, Hangzhou, China; ${ }^{3}$ Master Class, Zhejiang Chinese Medical University, Fourth School of Clinical \\ Medicine, Hangzhou, China; ${ }^{4}$ Master Class, Hangzhou Normal University, School of Medicine, Hangzhou, China; ${ }^{5}$ Department of Proctology, \\ Affiliated Hospital of Hangzhou Normal University, Hangzhou, China \\ Contributions: (I) Conception and design: Y Zhu, C Huang, J Chen; (II) Administrative support: J Chen; (III) Provision of study materials: Y Zhu, \\ C Huang; (IV) Collection and assembly of data: M Su, Z Ge, L Gao, Y Shi, X Wang; (V) Data analysis and interpretation: Y Zhu, C Huang; (VI) \\ Manuscript writing: All authors; (VII) Final approval of manuscript: All authors. \\ "These authors contributed equally to this work. \\ Correspondence to: Jianfeng Chen. Department of Proctology, Affiliated Hospital of Hangzhou Normal University, No. 126 Wenzhou Road, \\ Hangzhou 310000, China. Email: oneinlove_1@hotmail.com.
}

Background: The present study aimed to explore residues' properties interacting with HLA-A*02restricted peptides on T-cell receptors (TCRs) and their effects on bond types of interaction and binding free energy.

Methods: We searched the crystal structures of HLA-A*02-restricted peptide-TCR complexes from the Protein Data Bank (PDB) database and subsequently collected relevant parameters. We then employed Schrodinger to analyze the bond types of interaction and Gromacs 2019 to evaluate the TCR-antigen peptide complex's molecular dynamics simulation. Finally, we compared the changes of bond types of interaction and binding free energy before and after residue substitution to ensure consistency of the conditions before and after residue substitution.

Results: The main sites on the antigen peptides that formed the intermolecular interaction [hydrogen bond (HB) and pi stack] with TCRs were P4, P8, P2, and P6. The hydrophobicity of the amino acids inside or outside the disulfide bond of TCRs may be related to the intermolecular interaction and binding free energy between TCRs and peptides. Residues located outside the disulfide bond of TCR $\alpha$ or $\beta$ chains and forming pi stack force played favorable roles in the complex intermolecular interaction and binding free energy. The residues of the TCR $\alpha$ or $\beta$ chains that interacted with peptides were replaced by alanine (Ala) or glycine (Gly), and their intermolecular binding free energy of the complex had been improved. However, it had nothing to do with the formation of HB.

Conclusions: The findings of this study suggest that the hydrophobic nature of the amino acids inside or outside the disulfide bonds on the TCR may be associated with the intermolecular interaction and binding between the TCR and polypeptide. The residues located outside the TCR $\alpha$ or $\beta$ single-chain disulfide bond and forming the pi-stack force showed a beneficial effect on the intermolecular interaction and binding of the complex. In addition, the part of the residues on the TCR $\alpha$ or $\beta$ single chain that produced bond types of interaction with the polypeptide after being replaced by Ala or Gly, the intermolecular binding free energy of the complex was increased, regardless of whether $\mathrm{HB}$ was formed.

Keywords: Residues of T-cell receptors (residues of TCRs); interaction; HLA-A*02-restricted antigens; residue substitution; TCR-based immunotherapy

Submitted Jan 14, 2021. Accepted for publication Mar 24, 2021.

doi: $10.21037 / \mathrm{atm}-21-835$

View this article at: http://dx.doi.org/10.21037/atm-21-835

(c) Annals of Translational Medicine. All rights reserved. 


\section{Introduction}

T-cell receptors (TCRs) consist of 2 subunits, $\alpha$, and $\beta$, each of which contains a variable region ( $\mathrm{V}$ region) and a constant region (C region) (1). The $\mathrm{V}$ region of the TCR $\alpha$ and $\beta$ chains contain about 102-109 amino acids, and 3 regions in the $\mathrm{V}$ region have highly variable amino acid compositions and sequences known as complementarydetermining regions (CDRs). These are as follows: CDR1, CDR2, and CDR3 (2,3). The compositions and sequences of amino acids outside the CDRs are relatively difficult to change and framework regions (FRs), such as FR1, FR2, FR3, and FR4 (4). In the V region, 2 cysteines form disulfide bonds inside the chain to form a cyclic peptide containing about 50-60 amino acid residues, which is similar to the structure and function of the Immunoglobulin variable region $(\mathrm{IgV})$ region and is a domain that specifically recognizes foreign antigens $(5,6)$. TCR chains have chain centrality, that is, the $\alpha$ or $\beta$ chains of TCRs determine the specificity of major histocompatibility complex (MHC)restricted antigens, while the corresponding $\beta$ or $\alpha$ chains could regulate the affinity, activity, or cross-reaction of receptors without affecting antigen specificity (7-9). In the Han population, human leukocyte antigen (HLA)-A02 is the most common HLA-A allele, accounting for half of the population (data based on New allele frequency database, www.allelefrequencies.net) (10). Therefore, cell therapy based on HLA-A02 restricted epitope is more commonly used in the Chinese population (11). The interaction between TCR and potentially immunogenic peptides presented by MHC of antigen-presenting cells (APCs) is one of the most important mechanisms of the adaptive human immune system. A large number of structural simulations of the TCR-peptide-MHC system have been performed, and the large-scale study of the difference in kinetics between free TCR and pMHC-bound TCR is an important research aspect. There are significant differences in the kinetic characteristics of TCR between unbound TCR and TCR-pMHC simulations. Structural biology has demonstrated how $\mathrm{T}$ cell receptors bind to the peptideMHC complex and provides insights into the mechanisms of antigen specificity and cross-reactivity. Related researches have emphasized the influence of structural changes and molecular flexibility. In addition, the analysis of bond types of interactions and binding free energy plays an important role in TCR epitope prediction, antibody-antigen docking and TCR-peptide-MHC modeling (12-15). Docking score, interactions type (bond type and distance) and interaction with amino acids are carried out on a Glide module of Schrodinger Maestro 2019-2 MM Share Version (16-18). Molecular mechanics Poisson Boltzmann surface area (MM-PBSA) is a method of estimating the free energy of interaction, which has been increasingly used in the study of biomolecular interactions (19). GROMACS is used to calculate the relative free energy of protein-ligand binding $(20,21)$. Alanine (Ala) scanning mutagenesis is an experimental technique that sequentially mutates residues in a protein of interest to Ala. The goal is to identify certain residues that contribute the most to the free energy of the interaction. In the study of protein-protein interactions, such residues are usually called "hot spots" $(22,23)$. The function of protein is determined by the interaction between molecules, that is, the interaction between molecules is determined by physical and chemical surface characteristics such as geometry, electrostatic potential, hydrophobicity and concavity (24). Therefore, appropriate amino acid substitutions can produce protein mutants whose activity can be affected by the presence of new ligands through an allosteric mechanism. Glycine (Gly) is the smallest of the 20 natural amino acids. Substituting Gly for amino acids with large side chains seems to be the easiest way to obtain surface cavities. This is confirmed by all available structural analysis protein-small molecule interfaces (25). The protein region partially exposed to the solvent lacks large side chains, which is conducive to close contact with small organic molecules, thereby changing or regulating the activity of the protein (26-28). Given this background, we herein searched the crystal structure of HLA-A*02 restricted antigen peptide-TCR complexes from PDB. We subsequently explored the properties of amino acid residues located inside or outside the disulfide bond of TCR $\alpha$ and $\beta$ chains interacting with peptides and their effects on bond types of interaction and binding free energy.

\section{Methods}

\section{Crystal structure analysis}

The PDB was used to search the crystal structures of HLA$\mathrm{A}^{*} 02$-restricted peptide-TCR complexes (http://www.rcsb.org/) $(29,30)$. The following information was collected: PDB ID, HLA allele genotypes, complex names, resolution, and methods. Schrodinger's theory was applied to obtain the following information: residue closest, distance, specific interactions, hydrogen bond (HB), salt bridges, pi-stacking, and other parameters. 


\section{Molecular dynamic simulation optimization}

We employed Schrodinger to explore the bond types of interaction of the TCR- antigen peptide complex. In particular, the interaction between TCR and peptides was analyzed. Then, the residues on TCR, which produced intermolecular interactions such as $\mathrm{HB}$ and pi-stack, were screened and consequently replaced with Ala and Gly, respectively. After residue substitution, the structures of the proteins were constructed using Schrodinger and preserved as PDB structures. We then obtained protein complexes of residue substitution by pairing the antigen peptide with the protein structure after residue substitution and subsequently analyzing the types of interacting bonds. The resulting docked structures were further refined with molecular dynamics methods. All molecular dynamic analyses were performed with Groningen Machine for Chemical Simulations (GROMACS) 2019 (Development: Herman Berendsen Research Group, Department of Biophysical Chemistry, University of Groningen, Groningen, The Netherlands. Maintenance and update: Science for Life Laboratory, Stockholm University, Stockholm, Sweden). The simulation temperature was set to $300 \mathrm{~K}$, and the allatomic position of GROMACS and the simple point charge (SPC) water model were selected. The water molecules added around the protein formed a water box simulation system as a periodic boundary for dynamic simulation. In the process of simulation, the Particle-mesh Ewald (PME) algorithm was used. The long-range electrostatic interaction was calculated, and the integration step was set to $2 \mathrm{fs}$. Under the NVT [canonical ensemble, abbreviated as NVT, means that it has a certain number of particles $(\mathrm{N})$, volume $(\mathrm{V})$, and temperature $(\mathrm{T})$ ] ensemble, the system was balanced, and the water was optimized to $500 \mathrm{ps}$. The NPT [constant-pressure and constant-temperature, abbreviated as NPT, means that it has a certain number of particles $(\mathrm{N})$, pressure $(\mathrm{P})$, and temperature $(T)$ ] ensemble was used to balance the system to 500 ps. Finally, molecular dynamics simulations of 20 ns were conducted. Using peptides as ligands and proteins as receptors, the binding force between peptides and proteins was analyzed by Schrodinger. Ensuring that the conditions before and after residue replacement were similar, we compared the changes of bond types of interaction and binding free energy before and after residue replacement (31-34).

\section{Statistical analysis}

SPSS 19.0 software is used for statistical analysis, the data of each group is expressed by $\bar{x} \pm s$, and the comparison between multiple groups is analyzed by repeated measures Analysis of variance (ANOVA). $\mathrm{P}$ value less than 0.05 is considered to be statistically significant.

\section{Results}

\section{Screening of crystal structure of complex}

A total of 71 HLA-A*02-restricted peptide-TCR complexes were found from the PDB. Excluding autoimmune antigen peptides and the same crystal structures, 44 different complex crystal structures were screened. The PDB ID, allele genotype, source protein, resolution, and an analytical method for each crystal structure are shown in Table 1. The HLA allele genotype of all complexes was HLA-A*02. Most of the complex peptides were derived from viral antigens, such as HTLV-1, influenza M1, HCMV, Epstein-Barr virus, glycoprotein $100, \mathrm{HCV}$, and HIV p17, as well as tumorassociated antigens (TAAs), such as NY-ESO-1, MART1 , and hTER. The resolution of the crystal structure of all complexes ranged from 1.7 to $3.2 \AA$. The analytical method of all crystal structures was $\mathrm{X}$-ray diffraction.

\section{Residue sites on TCRs interacting with HLA-A*02- restricted peptides}

The residue sites of TCRs interacting with HLA-A*02restricted peptides and the initiation and end sites of corresponding disulfide bonds are shown in Table 2. As shown in Table 2, sequences referred to as polypeptide sequences, S-start and S-end referred to the beginning and end of disulfide bonds in the $\alpha$ or $\beta$ chain of TCRs, residue referred to the residues and their positions on the $\alpha$ or $\beta$ chain of TCRs that interacted with peptides, specific interactions referred to residues and types of interacting bonds (HB and pi stack) of peptides that interacted with TCR, and $\mathrm{C}$ referred to the antigen peptides.

The results suggested that the initial and terminal numbers of disulfide bonds in TCR $\alpha$ or $\beta$ single strands ranged from 21 to 28 , and from 87 to 104 , respectively. Among the intermolecular interactions formed by TCRs and polypeptides, HBs accounted for 126 of 132, and pi stacks accounted for 6 of 132 . Among the residue sites of polypeptides interacting with TCRs; $\mathrm{P} 4$ accounted for 45 of 132 (Gly 33/45; Ala 3/45; Asn, Lys, and Met 2/45; Glu, Ile, and Pro 1/45); P8 accounted for 25 of 132 (Tyr 12/25; Thr 6/25; Gln 4/25; Met, Trp, and Val 1/25); P2 accounted 
Table 1 Properties of HLA-A*02-restricted peptide-T-cell receptor crystal complexes

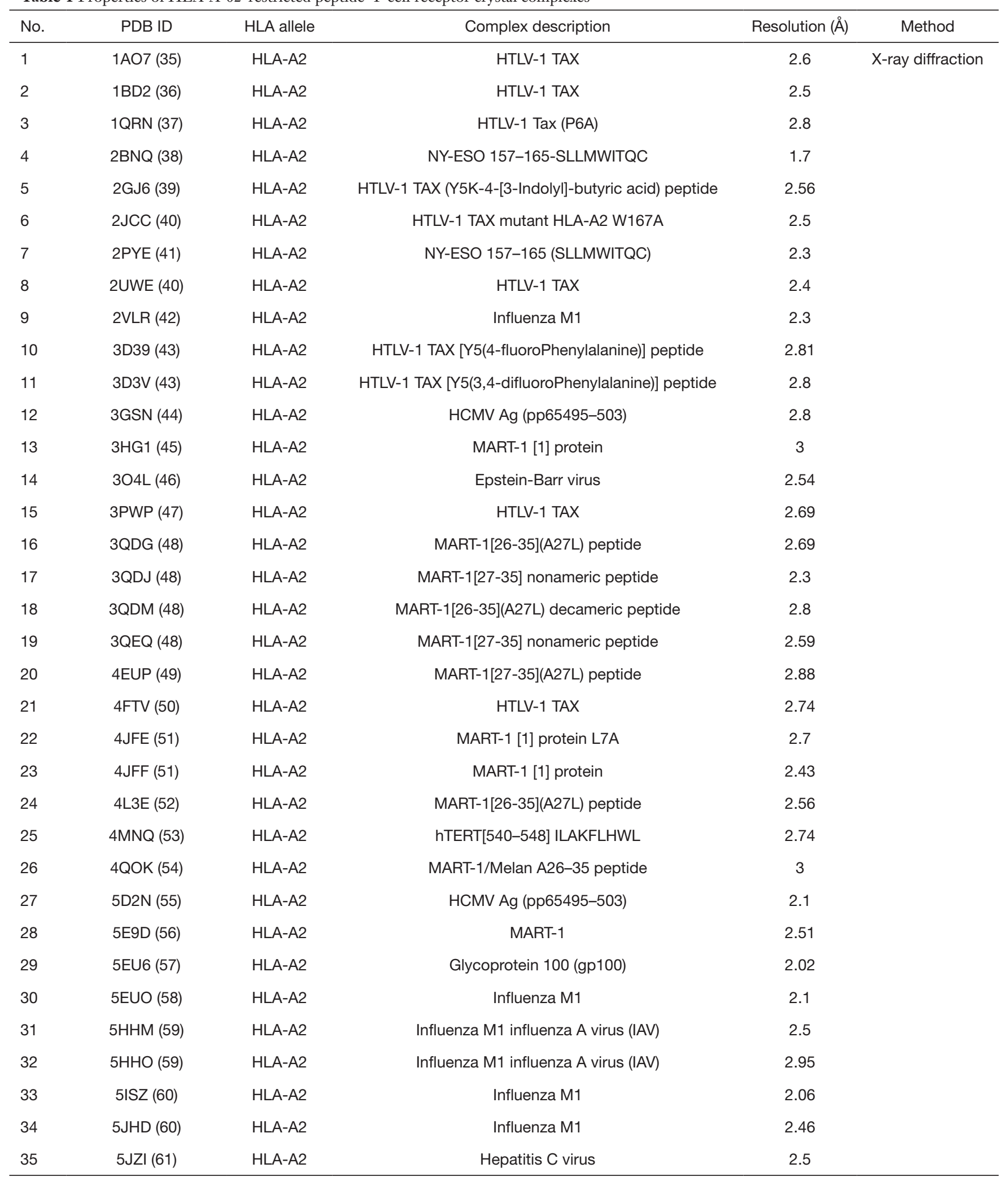

Table 1 (continued) 
Table 1 (continued)

\begin{tabular}{lcccc}
\hline No. & PDB ID & HLA allele & Complex description & Resolution (Å) \\
\hline 36 & 5NHT (62) & HLA-A2 & MART-1/Melan A26-35 peptide & 3.2 \\
37 & 5NMG (63) & HLA-A2 & HIV p17 Gag-derived & 2.75 \\
38 & 5TEZ (64) & HLA-A2 & Influenza M1 Influenza A virus & 1.7 \\
39 & 5YXN (65) & HLA-A2 & Hepatitis C virus NS3 peptide & 2.03 \\
40 & 5YXU (66) & HLA-A2 & Hepatitis C virus NS3 peptide & 2.7 \\
41 & 6D78 (67) & HLA-A2 & MART-1[27-35](alpha-D26Y,beta-L98W) peptide & 2.35 \\
42 & 6DKP (67) & HLA-A2 & MART-1[26-35](A27L)(alpha-D26Y, alpha-Y50A,beta-L98W) & 2.97 \\
43 & 6EQB (68) & HLA-A2 & peptide & 2.81 \\
44 & 6RPB (69) & HLA-A2 & MART-1 & 2.5 \\
\hline
\end{tabular}

for 16 of 132 (Leu 10/16, Ala 4/16, Gly 1/16, Ile 1/16); P6 accounted for 16 of 132 (Val 7/16, Ile 5/16, Gly 3/16, Tyr 1/16); P5 accounted for 11 of 132 (Trp 7/11, Tyr 2/11, Gly and Phe 1/11); P7 accounted for 11 of 132 (Ile 8/11, Thr 2/11, Ala 1/11); P1 accounted for 4 of 132 (Glu 3/4, Lys 1/4); P9 accounted for 3 of 132 (Thr 3/3); P3 was accounted for 1 of 132 (Gly 1/1). Among the amino acid residues on TCR interacting with peptides, Gly accounted for 39 of 132; Ile accounted for 15 of 132; Tyr accounted for 15 for 132; Thr accounted for 11 of 132; Leu accounted for 10 of 132; Ala accounted for 8 of 132; Trp accounted for 8 of 132; Val accounted for 8 of 132; Gln accounted for 4 of 132; Glu accounted for 4 of 132; Lys accounted for 3 of 132; Met accounted for 3 of 132; Asn accounted for 2 of 132; Phe accounted for 1 of 132; and Pro accounted for 1 of 132 . TCR and HLA-A*02 had no intermolecular interaction. Even for the same peptides, the residues and sites on the TCRs and the peptides corresponding to the intermolecular interactions were not the same.

\section{Amino acid properties of residues on TCRs interacting with peptides}

The amino acid properties of residues on TCRs that formed intermolecular interactions with antigen peptides are shown in Tables 3 and 4. Table 3 shows the residues' amino acid properties located inside the disulfide bond on the single strand of the TCR $\alpha$ chain that formed an HB or pi stack with peptides. The residues were located at positions 29, 30, 31, 37, and 68 of the TCR $\alpha$ chain, and the amino acid properties were mainly polar uncharged
(Ser and Gln), which formed HBs with polypeptides. An aromatic amino acid (Tyr) reacted with peptides to form pi stacks, and positively charged amino acid (Arg) reacted with peptides to form HBs. There was a diversity of amino acids at position 31, polar uncharged amino acids (Gln and Ser), and aromatic amino acids (Tyr). Table 4 shows the residues' amino acid properties located inside the disulfide bond on the single strand of the TCR $\beta$ chain that formed HBs with peptides. The residues were located at positions 26,28 , $30,32,33,37,48$, and 52 of the TCR $\beta$ chain. The amino acid properties were mainly polar uncharged (Asn and Gln) and negatively charged (Glu and Asp), which formed HBs with antigen peptides. There were various amino acids at position 28 , which could be polar uncharged amino acid (Asn) and negatively charged amino acid (Glu). Table 5 shows the residues' properties outside the disulfide bond on the TCR $\alpha$ chain that formed HBs or pi stack with peptides. The residues were located at positions 90, 92, 94, 95, 96, $98,100,101,102$, and 103 of the TCR $\alpha$ chain. The amino acid properties were mainly polar uncharged (Asn and Ser), non-polar aliphatic (Ala, Pro, Gly), negatively charged (Asp), and aromatic (Tyr). Except for the residues at position 103, all formed HBs with polypeptides. Tyr, at positions 100 and 103 , reacted with the antigen peptides to form a pi stack. Moreover, the residues of several binding sites were diverse, and the 94th position could be polar uncharged amino acids (Asn and Ser) and also be non-polar aliphatic amino acids (Ala and Pro). The 96th position was all non-polar aliphatic amino acids (Ala and Gly). The 98th position could be polar uncharged amino acid (Asn), non-polar aliphatic amino acid (Ala), and negatively charged amino acid (Asp). The 100th 
Table 2 Residues, sites, and Bond types of intermolecular interaction, between T-cell receptors and peptides

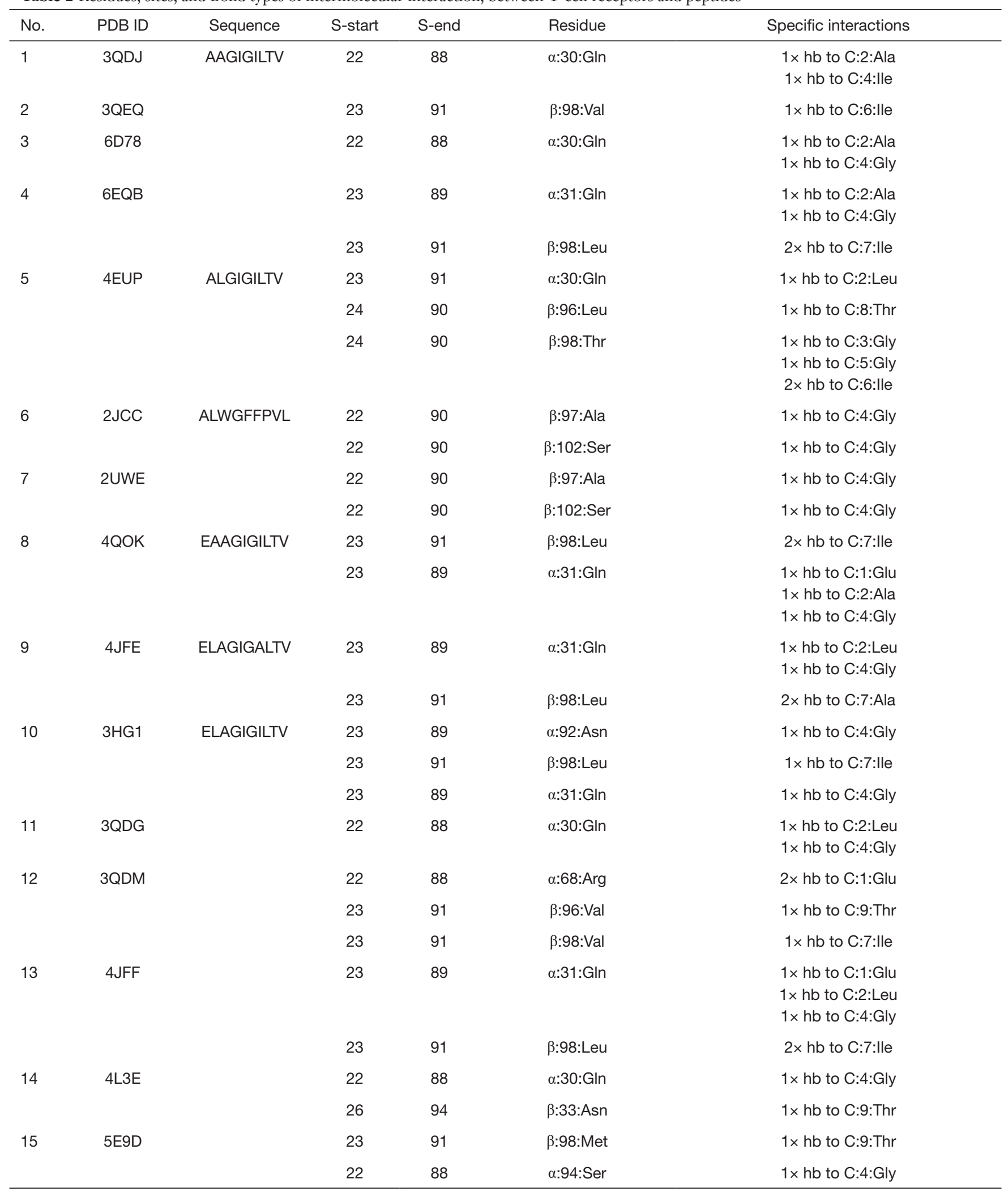

Table 2 (continued) 
Table 2 (continued)

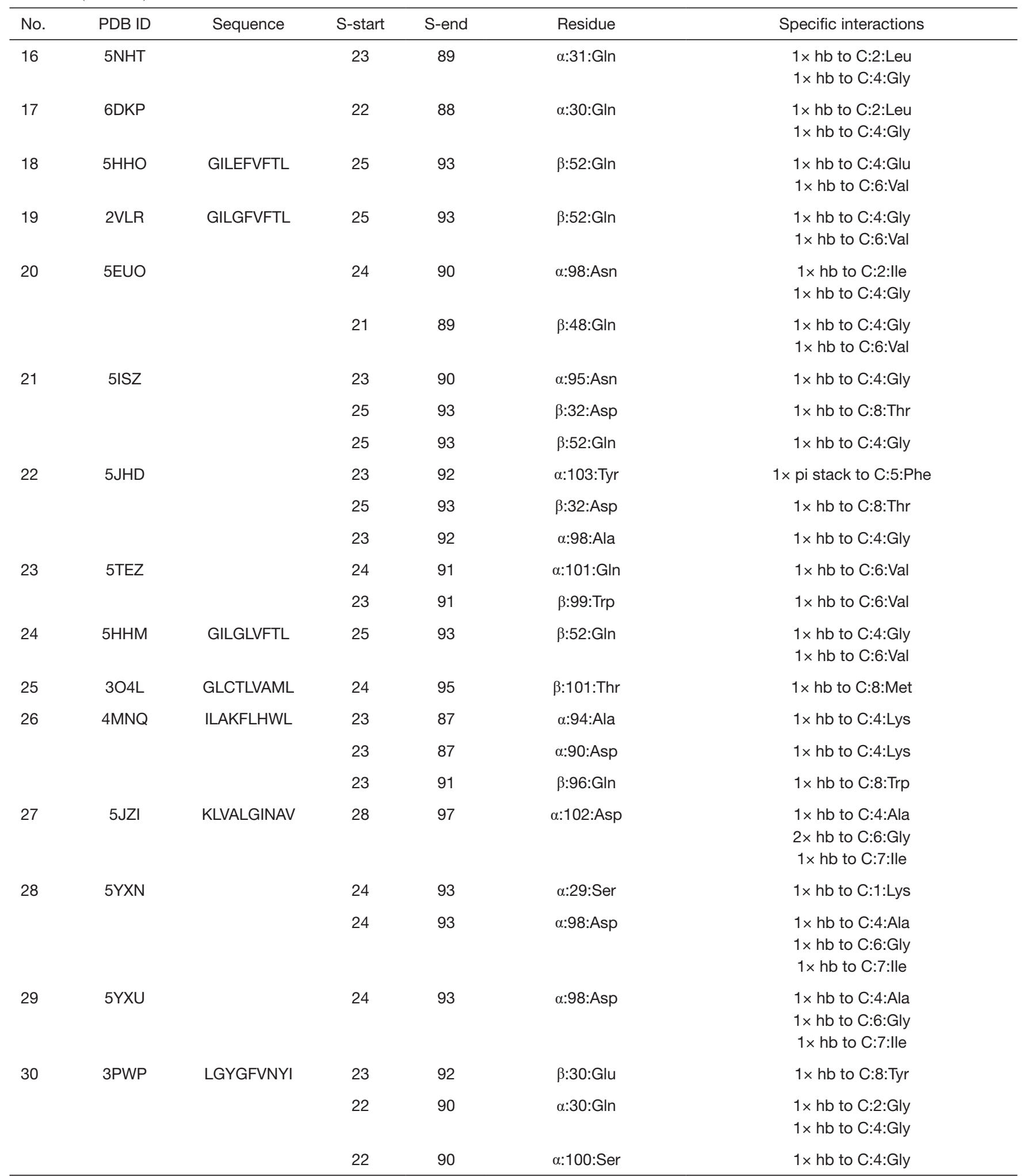

Table 2 (continued) 
Table 2 (continued)

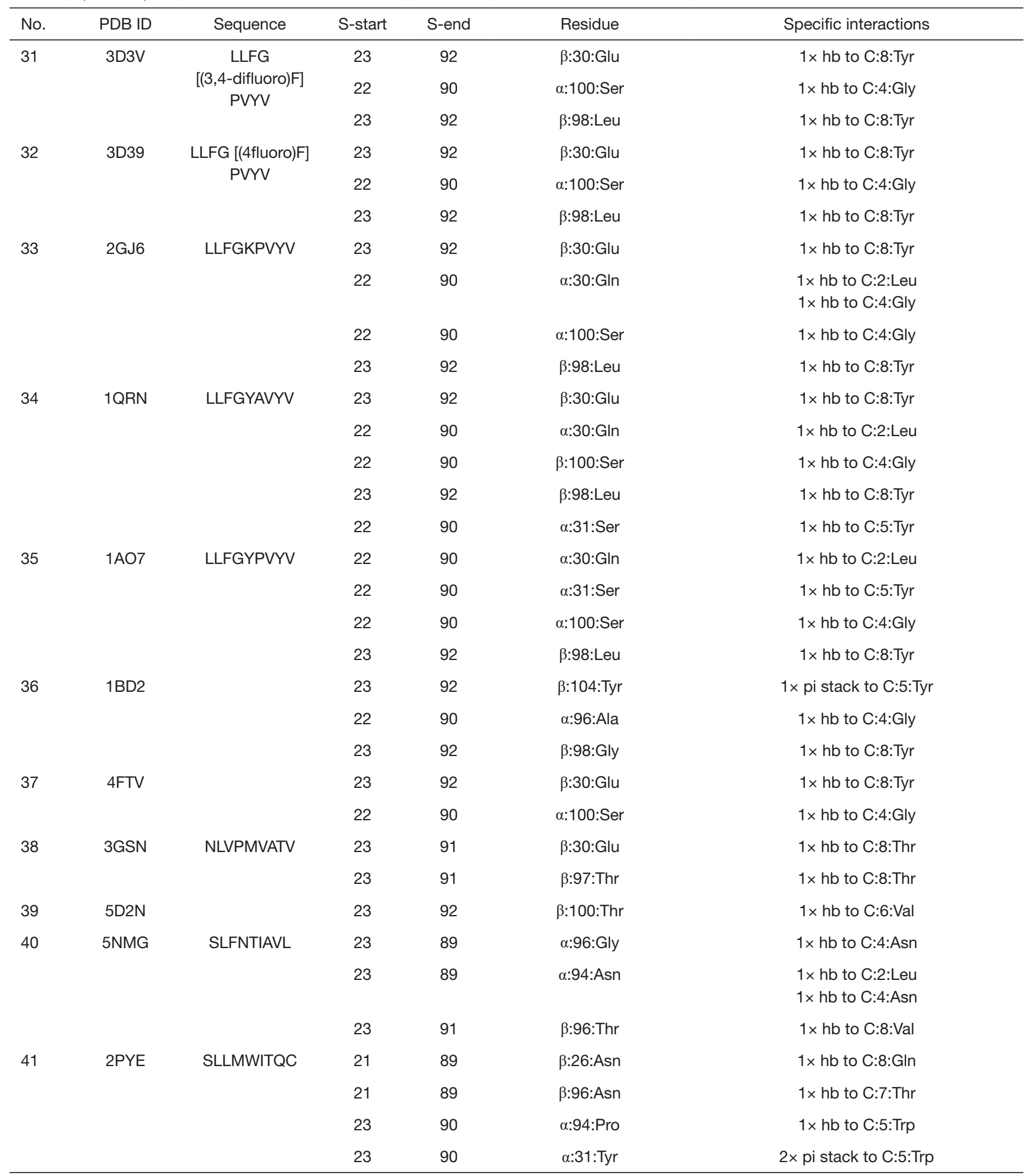

Table 2 (continued) 
Table 2 (continued)

\begin{tabular}{|c|c|c|c|c|c|c|}
\hline No. & PDB ID & Sequence & S-start & S-end & Residue & Specific interactions \\
\hline & & & 23 & 90 & $\alpha: 100: \operatorname{Tyr}$ & $\begin{array}{c}1 \times \text { hb to } C: 4: \text { Met } \\
1 \times \text { pi stack to } C: 5: \operatorname{Trp}\end{array}$ \\
\hline & & & 21 & 89 & $\beta: 28: G l u$ & $1 \times$ hb to $C: 8: G l n$ \\
\hline \multirow[t]{4}{*}{42} & $2 B N Q$ & SLLMWITQV & 23 & 90 & $\alpha: 94:$ Pro & $1 \times$ hb to $C: 5: \operatorname{Trp}$ \\
\hline & & & 23 & 90 & $\alpha: 31: T y r$ & $2 \times$ pi stack to $C: 5: \operatorname{Trp}$ \\
\hline & & & 23 & 90 & $\alpha: 100:$ Tyr & $\begin{array}{c}1 \times \text { hb to C:4:Met } \\
1 \times \text { pi stack to C:5:Trp }\end{array}$ \\
\hline & & & 22 & 90 & $\beta: 95: \mathrm{Val}$ & $1 \times \mathrm{hb}$ to $\mathrm{C}: 6: 1 \mathrm{le}$ \\
\hline \multirow{2}{*}{43} & & & 23 & 104 & $\beta: 109:$ Leu & $1 \times \mathrm{hb}$ to $\mathrm{C}: 6: \| \mathrm{le}$ \\
\hline & & & 23 & 104 & $\beta: 37:$ Glu & $1 \times \mathrm{hb}$ to $\mathrm{C}: 8: \mathrm{Gln}$ \\
\hline \multirow[t]{2}{*}{44} & 5EU6 & YLEPGPVTV & 24 & 91 & $\alpha: 101: T y r$ & $1 \times \mathrm{hb}$ to $\mathrm{C}: 4:$ Pro \\
\hline & & & 24 & 93 & $\beta: 98:$ Ile & $1 \times \mathrm{hb}$ to $\mathrm{C}: 8: \mathrm{Thr}$ \\
\hline
\end{tabular}

Table 3 Characteristics of residues inside the disulfide bond of the T-cell receptor (TCR) $\alpha$ chain

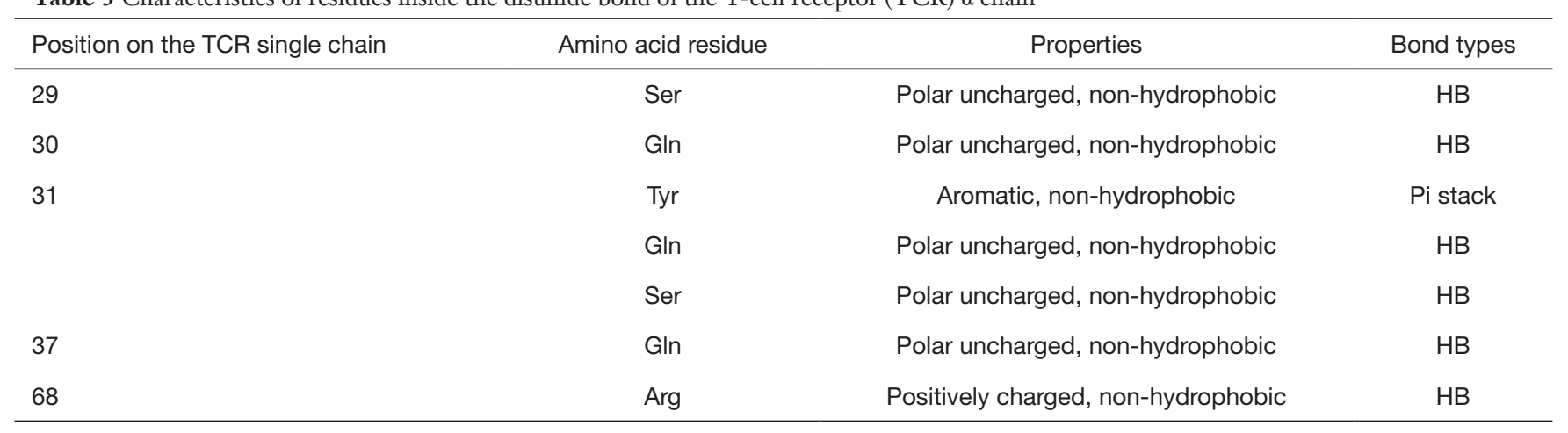

position could be polar uncharged (Ser) or aromatic (Tyr) amino acid. The 101st position could be polar uncharged (Gln) or aromatic (Tyr) amino acids. Table 6 shows the residues' properties outside the disulfide bond on the TCR $\beta$ chain that formed HB or pi stack with polypeptides. These residues were located at positions $94-102$ and 104-109 of the TCR $\beta$ chain and were mainly polar uncharged (Asn, Gln, Thr, and Ser), non-polar aliphatic (Leu, Val, Ala, Gly, Ile, and Met), and aromatic (Trp and Tyr) amino acids. Except for the 104th position, they were all formed HBs with the polypeptides. Tyr at the 104th position formed a pi stack with the polypeptide. Moreover, the amino acid residues of several binding sites were diverse. The 96th position could be polar uncharged amino acids (Asn, Gln, and Thr) or non-polar aliphatic amino acids (Leu and Val); the 97th position could be polar uncharged amino acid (Asn and Thr) or non-polar aliphatic amino acid (Ala); the 98th position could be non-polar aliphatic amino acids (Gly, Ile, Leu, Met, and Val) or polar uncharged amino acids (Thr); and the 100th position could be polar uncharged amino acids (Ser and Thr). Also, according to the hydrophobicity of the residues, we found that the 
Table 4 Characteristics of residues inside the disulfide bond of the T-cell receptor (TCR) $\beta$ chain

\begin{tabular}{|c|c|c|c|}
\hline Position on the TCR single chain & Amino acid residue & Properties & Bond types \\
\hline \multirow[t]{2}{*}{28} & Glu & Negatively charged, non-hydrophobic & $\mathrm{HB}$ \\
\hline & Asn & Polar uncharged, non-hydrophobic & $\mathrm{HB}$ \\
\hline 30 & Glu & Negatively charged, non-hydrophobic & $\mathrm{HB}$ \\
\hline 33 & Asn & Polar uncharged, non-hydrophobic & $\mathrm{HB}$ \\
\hline 37 & Glu & Negatively charged, non-hydrophobic & $\mathrm{HB}$ \\
\hline 48 & Gln & Polar uncharged, non-hydrophobic & HB \\
\hline 52 & Gln & Polar uncharged, non-hydrophobic & $\mathrm{HB}$ \\
\hline
\end{tabular}

Table 5 Characteristics of residues outside the disulfide bond of the T-cell receptor (TCR) $\alpha$ chain

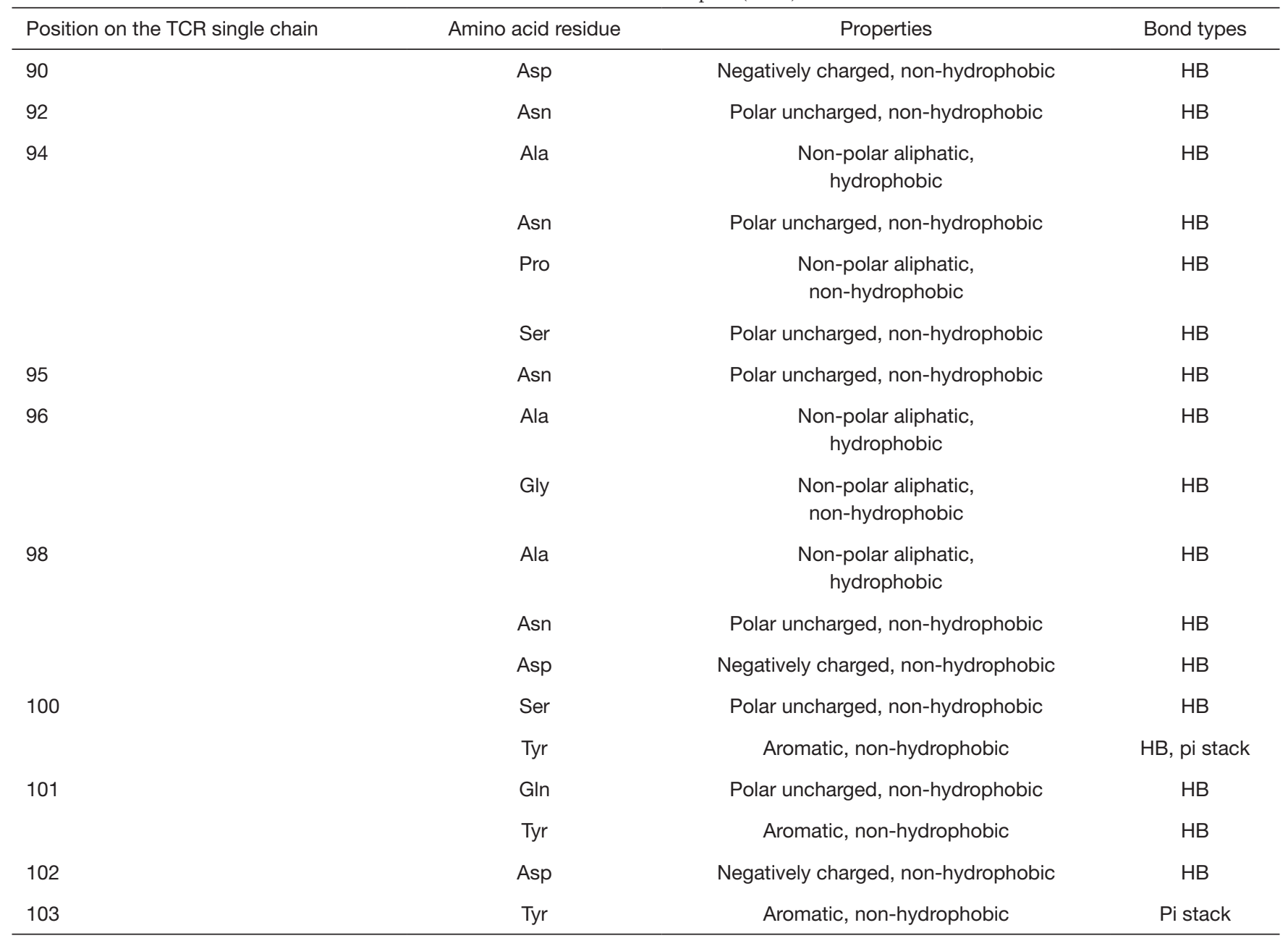


Table 6 Characteristics of residues outside the disulfide bond of the T-cell receptor (TCR) $\beta$ chain

\begin{tabular}{|c|c|c|c|}
\hline Position on the TCR single chain & Amino acid residue & Properties & Bond types \\
\hline 95 & Val & Non-polar aliphatic, hydrophobic & $\mathrm{HB}$ \\
\hline \multirow[t]{4}{*}{96} & Asn & Polar uncharged, non-hydrophobic & $\mathrm{HB}$ \\
\hline & Leu & Non-polar aliphatic, hydrophobic & $\mathrm{HB}$ \\
\hline & Thr & Polar uncharged, non-hydrophobic & $\mathrm{HB}$ \\
\hline & Val & Non-polar aliphatic, hydrophobic & $\mathrm{HB}$ \\
\hline \multirow[t]{2}{*}{97} & Ala & Non-polar aliphatic, hydrophobic & $\mathrm{HB}$ \\
\hline & Asn & Polar uncharged, non-hydrophobic & $\mathrm{HB}$ \\
\hline \multirow{5}{*}{98} & Ile & Non-polar aliphatic, hydrophobic & $\mathrm{HB}$ \\
\hline & Leu & Non-polar aliphatic, hydrophobic & $\mathrm{HB}$ \\
\hline & Met & Non-polar aliphatic, hydrophobic & $\mathrm{HB}$ \\
\hline & Thr & Polar uncharged, non-hydrophobic & $\mathrm{HB}$ \\
\hline & Val & Non-polar aliphatic, hydrophobic & $\mathrm{HB}$ \\
\hline 99 & Trp & Aromatic, non-hydrophobic & $\mathrm{HB}$ \\
\hline \multirow[t]{2}{*}{100} & Ser & Polar uncharged, non-hydrophobic & $\mathrm{HB}$ \\
\hline & Thr & Polar uncharged, non-hydrophobic & $\mathrm{HB}$ \\
\hline
\end{tabular}

residues inside the disulfide bond of the TCR $\alpha$ or $\beta$ singlechain were all non-hydrophobic amino acids; however, outside the disulfide bond, the residue of the TCR $\alpha$ singlechain located at the 94th, 96th, and 98th positions was Ala, which is a hydrophobic amino acid; the ones of the TCR $\beta$ single-chain located at the 94th (Leu), 95th (Val), 96th (Leu, Val), 97th (Ala), 98th (Ile, Leu, Met, Val), and 109th (Leu) positions were all hydrophobic amino acids. The abovementioned hydrophobic amino acids were all non-aliphatic amino acids, which formed HBs with polypeptides.

\section{Molecular dynamic simulation of peptides and TCRs}

As shown in Table 7, the highest binding free energy of the TCR and 1BD2 interaction was that Tyr at position 104 outside the disulfide bond of TCR $\beta$ chain formed a pi stack with Tyr at position 5 of the polypeptide, and its binding free energy was $-5.62 \mathrm{KJ} / \mathrm{mol}$. However, the lowest binding free energy was that Gly at position 98, located outside the disulfide bond in the $\beta$ chain, created $\mathrm{HB}$ with Tyr at position 8 of the antigen peptides with a binding free energy of $2.43 \mathrm{KJ} / \mathrm{mol}$. The highest binding free energy of the interaction between TCR and 4FTV was Ser at position 100, located outside the disulfide bond of the $\alpha$ chain, which formed HBs with Gly at position 4 of the polypeptide; binding free energy was $-2.66 \mathrm{KJ} / \mathrm{mol}$. The lowest binding free energy was Gly at position 30, located inside the disulfide bond of TCR $\beta$, which formed HBs with 
Table 7 Bond types and binding free energy of antigen peptides and T-cell receptors (TCRs)

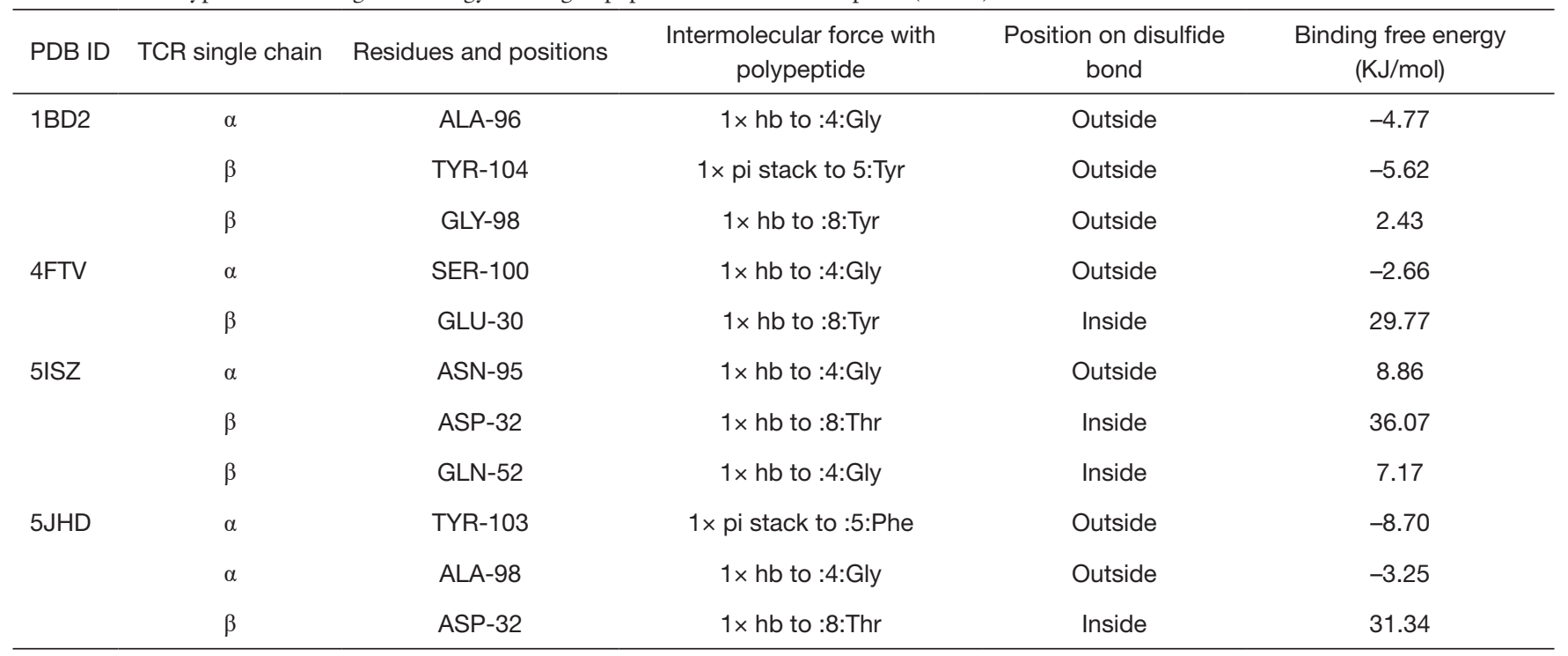

Tyr at position 8 of the polypeptide; its binding free energy was $29.77 \mathrm{KJ} / \mathrm{mol}$. The highest binding free energy of the interaction between TCR and 5ISZ was Gln at position 52 , located inside the disulfide bond of the $\beta$ chain, which formed HBs with Gly at position 4 of the polypeptide; its binding free energy was $7.17 \mathrm{KJ} / \mathrm{mol}$. The lowest binding free energy was Asp at position 32 inside the disulfide bond of the $\beta$ chain, which formed HBs with Thr at position 8 of the polypeptide; its binding free energy was $36.07 \mathrm{KJ} / \mathrm{mol}$. The highest binding free energy of the interaction between TCR and 5JHD was Tyr at position 103 outside the disulfide bond of the $\alpha$ chain, which formed a pi stack with Phe at position 5 of the polypeptide; its binding free energy was $-8.70 \mathrm{KJ} / \mathrm{mol}$. The lowest binding free energy was Asp at position 32 inside the disulfide bond of the $\beta$ chain, which formed HBs with Thr at position 8 of the polypeptide; its binding free energy was $31.34 \mathrm{KJ} / \mathrm{mol}$. As shown in Table 7 , the binding sites of polypeptides with the same sequence and their specific TCRs were mostly different. The binding free energy of residues located outside the TCR single chain's disulfide bond to the polypeptide was higher than that located inside the TCR single chain. The binding free energy of antigen peptides and TCR residues to form a pi stack was higher than that of HBs, and the residue of pi stack formation was located at position 5 of the polypeptide, Tyr, and Phe; their corresponding residue (Tyr) of the TCR single chain was at position 104 and 103. Furthermore, the residues were all aromatic amino acids.

\section{Effect of residue substitution on the interaction and binding free energy between polypeptides and TCR molecule}

To further understand the residues' influence in Table 7 on the polypeptide-HLA-TCR complex's intermolecular interactions, we replaced the 9 non-Ala residues with Ala (except Ala-96 and Ala-98), and 10 non-Gly residues were replaced with Gly (except Gly-98). The bond types of interaction and binding free energy changes after the residue replacement were analyzed (Tables 8 and 9 ). $\Delta \mathrm{E}=$ EBR - EAR (E was referred to as binding free energy; EBR was referred to as binding free energy before replacing; EAR was referred to as binding free energy after replacing). The higher the negative value, the more important were the residues before a replacement for the complex interaction and binding, while the higher the positive value, it was the opposite. A value of $\leq-3 \mathrm{KJ} / \mathrm{mol}$ was considered significant. As shown in Table 8, after the replacement of Ala, the pi stack force between position 104 outside the disulfide bond of the TCR $\beta$ chain and Tyr at position 5 of the polypeptide in 1BD2 disappeared, and its binding free energy also decreased, indicating that the original Tyr at position 104 was more favorable for the binding of the complex. Likewise, in 5JHD, the pi-stack force between position 103 outside the disulfide bond of the TCR $\alpha$ chain and Phe at position 5 of the polypeptide also disappeared, and its binding free energy was correspondingly reduced. This 
Table 8 Interaction force and binding free energy between polypeptides and T-cell receptor (TCR) molecule after alanine replacement

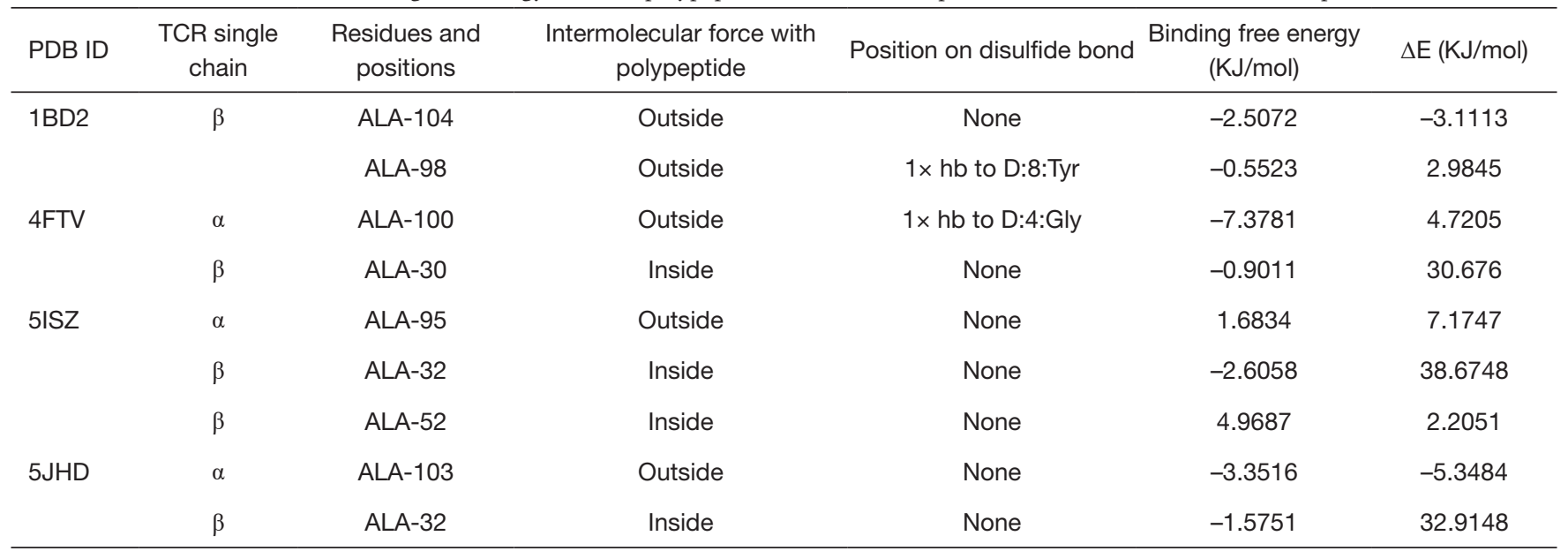

Table 9 Interaction and binding free energy between polypeptides and T-cell receptor (TCR) molecule after glycine replacement

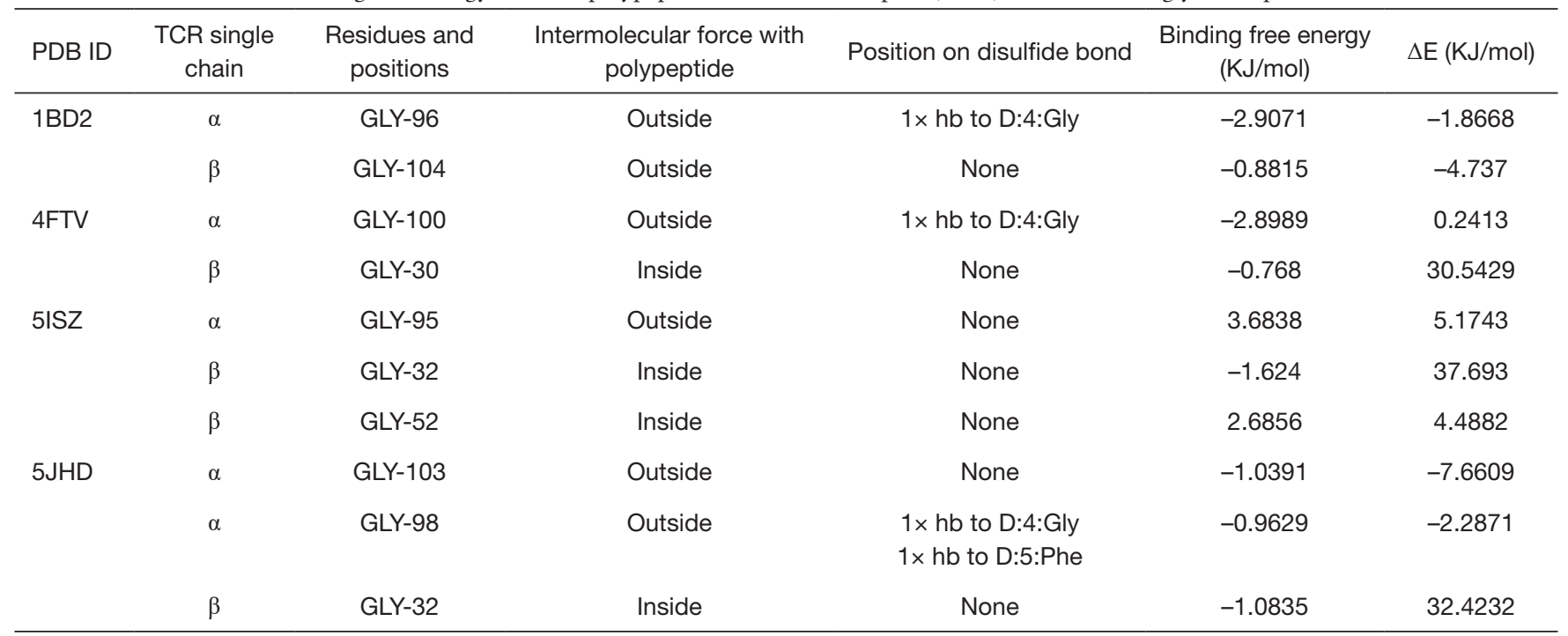

suggested that the original position of Tyr at 103 was more beneficial for the combination of complexes. However, the remaining residues on the TCR were replaced by Ala; their binding free energy was increased. We further found that the original residues at these sites might have adversely affected the complex binding. The results after replacing the corresponding non-Gly residues with Gly are given in Table 9, while similar findings are also shown in Table 8. These findings indicate that the residues (all aromatic nonhydrophobic amino acids) located outside the disulfide bonds of the TCR $\alpha$ or $\beta$ single-chain formed the pi stack force and had a beneficial effect on the intermolecular interaction of the complex. When Ala or Gly replaced the residues on the single chain of TCR $\alpha$ or $\beta$, the complex's intermolecular binding free energy may increase, regardless of whether an $\mathrm{HB}$ was formed.

\section{Discussion}

T cells used the TCR to search for various polypeptides presented by the MHC molecule with high sensitivity and specificity. Wu et al. found that the MHC mainly guided TCR docking in a peptide-independent manner, which determined the initial binding (70). Specifically, peptides dominate the stability and specificity of contacting TCR, affecting $\mathrm{T}$ cell activation by adjusting the binding time 
of the pMHC-I complex. This functional breakdown of peptide-MHC ligands has been shown that the two-step process of TCR recognition was assisted to effectively scan different peptide-MHC complexes on the cell surface, which made the TCR inherently cross-reacted with different peptides bound to the same MHC. Zhang et al. used site-directed mutagenesis to estimate the HLA-A2 side chain's contribution to the binding of the 4 TCRs (71). The findings indicated that these TCRs had a different energy footprint from that of HLA-A2, and no residue was involved in the interaction with all TCRs. MHC side chains' total contribution to the total interaction energy was variable, and the lower limit ranged from $11-50 \%$. The molecular dynamic analysis found that MHC side chains' contribution to transition state complexes was small and variable. Madura et al. found that the suboptimal anchor residue at position 2 of the peptide allowed the TCR to pull the antigen peptides from the MHC binding groove, thereby facilitating additional contact with the peptide and the MHC surface (54). Our results suggested that the TCR single-chain had no intermolecular interaction with HLA-A*02. The intermolecular interaction between the TCR and polypeptide was mainly an HB, followed by a pi stack.

Human TCR has a strong ability to combine with polymorphic, positively charged hot spot regions, which are almost exclusively unique to the human HLA-A*02 spiral (72). The TCR bonding process requires hot spots to be embedded, resulting in high energy loss offset by complementary electrostatic interactions. The enrichment of negative charges in the TCR binding loop, especially the germline loop encoded by the TCRV $\alpha$ and $\mathrm{V} \beta$ genes, enables this to occur and is related to the restricted localization of TCR on HLA-A2 (73). Yu et al. also found that the bicyclic loops of TCR $\alpha$ and $\beta$ chains contain many charged polar residues (73). The amino acids in the CDR3 loop region located on the TCR $\alpha$ and $\beta$ chains are significantly different, and each chain has a special role in recognizing the antigen-MHC complex. In the present study, the 98th position inside the disulfide bond of the TCR $\alpha$ chain, which produced the intermolecular interaction force with the HLA-A*02 polypeptide, was a negatively charged amino acid (Asp), and the 28th position inside the disulfide bond of TCR $\beta$ chain was a negatively charged amino acid (Glu). According to the hydrophobic nature of amino acids, the residues inside the disulfide bond of the TCR $\alpha$ or $\beta$ single-chain were all non-hydrophobic amino acids, while the residue of TCR outside the disulfide bond at the 94th, 96th, and 98th positions of the $\alpha$ singlechain were Ala (hydrophobic amino acid). The 94th (Leu), 95th (Val), 96th (Leu, Val), 97th (Ala), 98th (Ile, Leu, Met, Val), and 109th (Leu) positions of the $\beta$ single-chain were all hydrophobic amino acids. Moreover, the above-mentioned hydrophobic amino acids were all non-aliphatic amino acids and formed HBs with polypeptides. It was suggested that the hydrophobic nature of the amino acids inside or outside the disulfide bond on the TCR might be related to the interaction between the TCR and the polypeptide; however, further research is warranted.

HLA class I antigens are combined with non-self or abnormally expressed peptides, and then newly formed HLA-I-peptide complexes are presented to T lymphocytes, playing a key role in immune recognition of transformed and virally infected cells (74). The recognition of TAA by HLA-I restricted CTL cells is the main feature of detecting and destroying malignant cells (75). The discovery and molecular characterization of TAA has changed the field of cancer treatment and introduced a new era of cancer immunotherapy, aiming to improve tumor immunogenicity and $\mathrm{T}$ cell-mediated anti-tumor immunity (76). This interaction is usually stabilized by the interaction between the HLA surface and the CDR loops 1 and 2 encoded by the TCR germline, while the selectivity of the antigen peptides is guided by direct interaction with the TCR CDR3 loop. Coles et al. elucidated that TCR sensed the first residue of the peptide through the residue Trp-167 on HLA, and this residue acted as an adjustable gateway (77). The substitution of the first amino acid of the polypeptide was estimated to change the side-chain conformation of HLA-Trp-167, thereby canceling the binding to TCR. Tripathi et al. found that the $\beta$-chain loop of TCR had the smallest change (78), suggesting that the $\beta$-domain of TCR could promote the interaction with the antigen. Goyarts et al. found that point mutations in certain positions in the CDR3 $\beta$ loop lost the ability to recognize antigen peptides (79), while mutations in other CDR3 $\beta$ positions caused a wide range of antigen recognition patterns on the MHC-peptide surface. This unique recognition ability was generated with minimal changes to the TCR CDR3 loop. These observations indicate that the extensive changes in recognition patterns due to minor perturbations in the structure of CDR3 appeared to be a structural strategy for generating a highly diverse TCR library specific to multiple antigens. Wang et al. modified the new TCR by introducing amino acid substitutions in CDR2 and CDR3 regions to improve its activity. As a result, this study showed that the 
ability of PBL to recognize tumors after TCR transduction with retroviruses was reduced or unchanged due to the substitution of residues in the CDR2 $\alpha$ region of the TCR $\beta$ chain. However, some residue substitutions, particularly in the 109th and 112th in $\alpha$ regions of CDR3, can enhance tumor recognition (80). For instance, phenylalanine substitution for tyrosine at residue 109 (109Y-F) and the substitution of Ala or lysine for serine at residue 112 (112S$\mathrm{K}$ or $112 \mathrm{~S}-\mathrm{A})$ can improve tumor recognition.

Furthermore, it has been reported that the combination of amino acid substitution and retrovirus encoding modified TCR109Y-F/112S-K can give the transduced PBL better tumor recognition ability. Wang et al. found that for a given polypeptide, a polypeptide-specific and highly conserved amino acid could always be identified at position 98 of the $\beta$ loop of TCRCDR3 (81). When the VSV peptide was replaced at position 6 , it led to compensatory changes in the 98th amino acid residue of the $\beta$ loop of TCRCDR3 and the CDR3 $\beta$ chain's length. It was suggested that the 98th amino acid residue of CDR3VSV/H-2kb was the key residue that determines the specificity of the TCR-VSV/ $\mathrm{H}-2 \mathrm{~kb}$ interaction, and a CDR3 $\beta$ loop of a specific length was required to promote this interaction (81). Zhang et al. observed that, in VSV8-specific CTL, position 93 of the $\alpha$ chain of CDR3 was a highly conserved residue (82), and certain substitutions of residues at position 4 of the polypeptide caused a change in position 93. It was indicated that there might be an interaction between the CDR $3 \alpha$ chain and the 4 th position of the polypeptide. The replacement of position 6 of VSV8 with a negatively charged residue also resulted in the change of position 93 of the CDR3 $\alpha$ chain to a positively charged residue, which indicated that the CDR3 $\alpha$ chain might interact with position 6 in some cases. In this study, we found that the positions and residues of HLA-A*02 polypeptides that formed intermolecular interactions with TCR $\alpha$ or $\beta$ chains were mainly P4 (Gly, Ala), P8 (Tyr, Thr, Gln), P2 (Leu, Ala), and P6 (Val, Ile, Gly). Subsequently, changing the amino acids in the above positions may affect the binding of HLA-A*02 polypeptides to TCR. To confirm this speculation, further experiments were needed. In this regard, we used $\mathrm{Ala}$ and Gly to replace the residues on the TCR that interacted with the polypeptide. Our result revealed that the residues (both aromatic and non-hydrophobic) located outside the TCR $\alpha$ or $\beta$ single-chain disulfide bond and forming the pistack force exhibited a beneficial effect on the interaction and binding of complex molecules. Besides, after the residues on the TCR $\alpha$ or $\beta$ single chain that produced types of interacting bondss with the polypeptide were replaced by Ala or Gly, the intermolecular binding free energy of the complex was increased, suggesting that it was more favorable for the combination of the two. We also observed that this combination had nothing to do with the formation of HB. In summary, this study provides a certain preliminary basis for the difficulty of how to modify TCR through residue substitution to increase the binding of TCR to HLA*A02 restricted antigen. However, its underlying mechanism is still unclear and thus requires further exploration.

\section{Conclusions}

In summary, the findings of this study suggest that the residue sites of HLA-A*02-polypeptides that formed HB and pi-stack with TCR, were primarily $\mathrm{P} 4, \mathrm{P} 8, \mathrm{P} 2$, and P6. The hydrophobic nature of the amino acids inside or outside the disulfide bonds on the TCR may be associated with the intermolecular interaction and binding between the TCR and polypeptide. The residues located outside the TCR $\alpha$ or $\beta$ single-chain disulfide bond and forming the pi-stack showed a beneficial effect on the intermolecular interaction and binding of the complex. We also noted that part of the residues on the TCR $\alpha$ or $\beta$ single chain that produced bond types of interaction with the polypeptide after being replaced by Ala or Gly, the intermolecular binding free energy of the complex was increased, regardless of whether HB was formed. Finally, this study provides a valuable theoretical basis for how to modify the TCR, that is, to improve the affinity and stability between the TCR and antigen peptides, and further to promote the binding between the two under the premise of ensuring the specificity of the antigens.

\section{Acknowledgments}

Funding: The study was supported by the Youth Project of the National Natural Science Foundation of China (No. 82004129) and the Sci-Tech Key Project of Zhejiang Province of China (No. 2017C03053).

\section{Footnote}

Conflicts of Interest: All authors have completed the ICMJE uniform disclosure form (available at http://dx.doi. org/10.21037/atm-21-835). The authors have no conflicts of interest to declare. 
Ethical Statement: The authors are accountable for all aspects of the work in ensuring that questions related to the accuracy or integrity of any part of the work are appropriately investigated and resolved.

Open Access Statement: This is an Open Access article distributed in accordance with the Creative Commons Attribution-NonCommercial-NoDerivs 4.0 International License (CC BY-NC-ND 4.0), which permits the noncommercial replication and distribution of the article with the strict proviso that no changes or edits are made and the original work is properly cited (including links to both the formal publication through the relevant DOI and the license). See: https://creativecommons.org/licenses/by-nc-nd/4.0/.

\section{References}

1. Garcia KC, Degano M, Stanfield RL, et al. An alphabeta $\mathrm{T}$ cell receptor structure at $2.5 \mathrm{~A}$ and its orientation in the TCR-MHC complex. Science 1996;274:209-19.

2. Wong WK, Leem J, Deane CM. Comparative Analysis of the CDR Loops of Antigen Receptors. Front Immunol 2019;10:2454.

3. Chlewicki LK, Holler PD, Monti BC, et al. Highaffinity, peptide-specific $\mathrm{T}$ cell receptors can be generated by mutations in CDR1, CDR2 or CDR3. J Mol Biol 2005;346:223-39.

4. Lake DF, Schluter SF, Wang E, et al. Autoantibodies to the alpha/beta T-cell receptors in human immunodeficiency virus infection: dysregulation and mimicry. Proc Natl Acad Sci U S A 1994;91:10849-53.

5. Xu JL, Davis MM. Diversity in the CDR3 region of $\mathrm{V}(\mathrm{H})$ is sufficient for most antibody specificities. Immunity 2000;13:37-45.

6. Xu C, Call ME, Wucherpfennig KW. A membraneproximal tetracysteine motif contributes to assembly of CD3deltaepsilon and CD3gammaepsilon dimers with the T cell receptor. J Biol Chem 2006;281:36977-84.

7. Nakatsugawa M, Rahman MA, Yamashita Y, et al. CD4(+) and CD8(+) TCR $\beta$ repertoires possess different potentials to generate extraordinarily high-avidity $\mathrm{T}$ cells. Sci Rep 2016;6:23821.

8. Thomas S, Stauss HJ, Morris EC. Molecular immunology lessons from therapeutic T-cell receptor gene transfer. Immunology 2010;129:170-7.

9. Nakatsugawa $M$, Yamashita $Y$, Ochi T, et al. Specific roles of each TCR hemichain in generating functional chaincentric TCR. J Immunol 2015;194:3487-500.
10. Liu S, Sun J, Li Z, et al. T Cell Therapy Targeted on HLA-A02 Restricted HIV Antigen Epitopes: An Open Label Cellular Therapy Trial Using CD8+ T Cell. Front Immunol 2019;10:437.

11. Dong T, Zhang Y, Xu KY, et al. Extensive HLA-driven viral diversity following a narrow-source HIV-1 outbreak in rural China. Blood 2011;118:98-106.

12. Teraguchi S, Saputri DS, Llamas-Covarrubias MA, et al. Methods for sequence and structural analysis of $\mathrm{B}$ and T cell receptor repertoires. Comput Struct Biotechnol J 2020;18:2000-11.

13. Knapp B, van der Merwe PA, Dushek O, et al. MHC binding affects the dynamics of different $\mathrm{T}$-cell receptors in different ways. PLoS Comput Biol 2019;15:e1007338.

14. Dominguez JL, Knapp B. How peptide/MHC presence affects the dynamics of the LC13 T-cell receptor. Sci Rep 2019;9:2638.

15. Baker BM, Scott DR, Blevins SJ, et al. Structural and dynamic control of T-cell receptor specificity, crossreactivity, and binding mechanism. Immunol Rev 2012;250:10-31.

16. Sinha SK, Shakya A, Prasad SK, et al. An in-silico evaluation of different Saikosaponins for their potency against SARS-CoV-2 using NSP15 and fusion spike glycoprotein as targets. J Biomol Struct Dyn 2020. [Epub ahead of print]. doi: 10.1080/07391102.2020.1762741.

17. Panwar U, Singh SK. Identification of Novel Pancreatic Lipase Inhibitors Using In Silico Studies. Endocr Metab Immune Disord Drug Targets 2019;19:449-57.

18. Moulishankar A, Lakshmanan K. Data on molecular docking of naturally occurring flavonoids with biologically important targets. Data Brief 2020;29:105243.

19. Kumari R, Kumar R, Lynn A. g_mmpbsa--a GROMACS tool for high-throughput MM-PBSA calculations. J Chem Inf Model 2014;54:1951-62.

20. Suruzhon M, Senapathi T, Bodnarchuk MS, et al. ProtoCaller: Robust Automation of Binding Free Energy Calculations. J Chem Inf Model 2020;60:1917-21.

21. Aragones JL, Noya EG, Valeriani C, et al. Free energy calculations for molecular solids using GROMACS. J Chem Phys 2013;139:034104.

22. London N, Raveh B, Schueler-Furman O. Druggable protein-protein interactions--from hot spots to hot segments. Curr Opin Chem Biol 2013;17:952-9.

23. Cunningham BC, Wells JA. High-resolution epitope mapping of hGH-receptor interactions by alaninescanning mutagenesis. Science 1989;244:1081-5.

24. Tee WV, Guarnera E, Berezovsky IN. Reversing allosteric 
communication: From detecting allosteric sites to inducing and tuning targeted allosteric response. PLoS Comput Biol 2018;14:e1006228.

25. Chen K, Kurgan L. Investigation of atomic level patterns in protein--small ligand interactions. PLoS One 2009; 4:e4473.

26. Qiu Y, Mekkat A, Yu H, et al. Collagen Gly missense mutations: Effect of residue identity on collagen structure and integrin binding. J Struct Biol 2018;203:255-62.

27. Chhum P, Yu H, An B, et al. Consequences of Glycine Mutations in the Fibronectin-binding Sequence of Collagen. J Biol Chem 2016;291:27073-86.

28. Bongini P, Niccolai N, Bianchini M. Glycineinduced formation and druggability score prediction of protein surface pockets. J Bioinform Comput Biol 2019;17:1950026.

29. Burley SK, Berman HM, Bhikadiya C, et al. RCSB Protein Data Bank: biological macromolecular structures enabling research and education in fundamental biology, biomedicine, biotechnology and energy. Nucleic Acids Res 2019;47:D464-74.

30. Berman HM, Westbrook J, Feng Z, et al. The Protein Data Bank. Nucleic Acids Res 2000;28:235-42.

31. Zhu K, Day T, Warshaviak D, et al. Antibody structure determination using a combination of homology modeling, energy-based refinement, and loop prediction. Proteins 2014;82:1646-55.

32. Sastry GM, Adzhigirey M, Day T, et al. Protein and ligand preparation: parameters, protocols, and influence on virtual screening enrichments. J Comput Aided Mol Des 2013;27:221-34.

33. Salam NK, Nuti R, Sherman W. Novel method for generating structure-based pharmacophores using energetic analysis. J Chem Inf Model 2009;49:2356-68.

34. Farid R, Day T, Friesner RA, et al. New insights about HERG blockade obtained from protein modeling, potential energy mapping, and docking studies. Bioorg Med Chem 2006;14:3160-73.

35. Garboczi DN, Ghosh P, Utz U, et al. Structure of the complex between human T-cell receptor, viral peptide and HLA-A2. Nature 1996;384:134-41.

36. Ding YH, Smith KJ, Garboczi DN, et al. Two human T cell receptors bind in a similar diagonal mode to the HLAA2 Tax peptide complex using different TCR amino acids. Immunity 1998;8:403-11.

37. Ding YH, Baker BM, Garboczi DN, et al. Four A6-TCR/ peptide/HLA-A2 structures that generate very different $\mathrm{T}$ cell signals are nearly identical. Immunity 1999;11:45-56.
38. Chen JL, Stewart-Jones G, Bossi G, et al. Structural and kinetic basis for heightened immunogenicity of $T$ cell vaccines. J Exp Med 2005;201:1243-55.

39. Gagnon SJ, Borbulevych OY, Davis-Harrison RL, et al. T cell receptor recognition via cooperative conformational plasticity. J Mol Biol 2006;363:228-43.

40. Miller PJ, Pazy Y, Conti B, et al. Single MHC mutation eliminates enthalpy associated with $\mathrm{T}$ cell receptor binding. J Mol Biol 2007;373:315-27.

41. Sami M, Rizkallah PJ, Dunn S, et al. Crystal structures of high affinity human T-cell receptors bound to peptide major histocompatibility complex reveal native diagonal binding geometry. Protein Eng Des Sel 2007;20:397-403.

42. Ishizuka J, Stewart-Jones GB, van der Merwe A, et al. The structural dynamics and energetics of an immunodominant T cell receptor are programmed by its Vbeta domain. Immunity 2008;28:171-82.

43. Piepenbrink KH, Borbulevych OY, Sommese RF, et al. Fluorine substitutions in an antigenic peptide selectively modulate $T$-cell receptor binding in a minimally perturbing manner. Biochem J 2009;423:353-61.

44. Gras S, Saulquin X, Reiser JB, et al. Structural bases for the affinity-driven selection of a public TCR against a dominant human cytomegalovirus epitope. J Immunol 2009;183:430-7.

45. Cole DK, Yuan F, Rizkallah PJ, et al. Germ line-governed recognition of a cancer epitope by an immunodominant human T-cell receptor. J Biol Chem 2009;284:27281-9.

46. Miles JJ, Bulek AM, Cole DK, et al. Genetic and structural basis for selection of a ubiquitous $T$ cell receptor deployed in Epstein-Barr virus infection. PLoS Pathog 2010;6:e1001198.

47. Borbulevych OY, Piepenbrink KH, Baker BM. Conformational melding permits a conserved binding geometry in TCR recognition of foreign and self molecular mimics. J Immunol 2011;186:2950-8.

48. Borbulevych OY, Santhanagopolan SM, Hossain M, et al. TCRs used in cancer gene therapy cross-react with MART-1/Melan-A tumor antigens via distinct mechanisms. J Immunol 2011;187:2453-63.

49. Hossain M, Baker BM. Structural description of how different MART-1 antigenic peptides influence JKF6 T cell receptor recognition. Available online: http://www. rcsb.org/structure/4EUP

50. Borbulevych OY, Baker BM. Structure of a high affinity TCR reveals native binding to MHC with enhanced peptide specificity. Available online: http://www.rcsb.org/ structure/4FTV 
51. Madura F, Rizkallah PJ, Miles KM, et al. T-cell receptor specificity maintained by altered thermodynamics. J Biol Chem 2013;288:18766-75.

52. Pierce BG, Hellman LM, Hossain M, et al. Computational design of the affinity and specificity of a therapeutic $\mathrm{T}$ cell receptor. PLoS Comput Biol 2014;10:e1003478.

53. Cole DK, Miles KM, Madura F, et al. T-cell receptor (TCR)-peptide specificity overrides affinity-enhancing TCR-major histocompatibility complex interactions. J Biol Chem 2014;289:628-38.

54. Madura F, Rizkallah PJ, Holland CJ, et al. Structural basis for ineffective T-cell responses to MHC anchor residue-improved "heteroclitic" peptides. Eur J Immunol 2015;45:584-91.

55. Yang X, Gao M, Chen G, et al. Structural Basis for Clonal Diversity of the Public T Cell Response to a Dominant Human Cytomegalovirus Epitope. J Biol Chem 2015;290:29106-19.

56. Harris DT, Singh NK, Cai Q, et al. An Engineered Switch in T Cell Receptor Specificity Leads to an Unusual but Functional Binding Geometry. Structure 2016;24:1142-54.

57. Bianchi V, Bulek A, Fuller A, et al. A Molecular Switch Abrogates Glycoprotein 100 (gp100) T-cell Receptor (TCR) Targeting of a Human Melanoma Antigen. J Biol Chem 2016;291:8951-9.

58. Yang X, Mariuzza RA. Crystal structure of PF6-M1HLA-A2 complex. Available online: http://www.rcsb.org/ structure/5EUO

59. Valkenburg SA, Josephs TM, Clemens EB, et al. Molecular basis for universal HLA-A*0201-restricted CD8+ T-cell immunity against influenza viruses. Proc Natl Acad Sci U S A 2016;113:4440-5.

60. Song I, Gil A, Mishra R, et al. Broad TCR repertoire and diverse structural solutions for recognition of an immunodominant CD8(+) T cell epitope. Nat Struct Mol Biol 2017;24:395-406.

61. Wang Y, Singh NK, Spear TT, et al. How an alloreactive T-cell receptor achieves peptide and MHC specificity. Proc Natl Acad Sci U S A 2017;114:E4792-e801.

62. Exertier C, Reiser JB, Housset D. human 199.54-16 TCR in complex with Melan-A/MART-1 (26-35) peptide and HLA-A2. Available online: http://www.rcsb.org/ structure/5NHT

63. Cole DK, Fuller A, Dolton G, et al. Dual Molecular Mechanisms Govern Escape at Immunodominant HLA A2-Restricted HIV Epitope. Front Immunol 2017;8:1503.

64. Yang X, Chen G, Weng NP, et al. Structural basis for clonal diversity of the human $\mathrm{T}$-cell response to a dominant influenza virus epitope. J Biol Chem 2017;292:18618-27.

65. Hui F. Capturing HCV immune escape by targeting structural based mechanism. Available online: http://www. rcsb.org/structure/5YXN

66. Yi L. an affinity enhanced $\mathrm{T}$ cell receptor in complex with HLA-A0201 restricted HCV NS3 peptide KLVALGINAV. Available online: http://www.rcsb.org/structure/5YXU

67. Hellman LM, Foley KC, Singh NK, et al. Improving T Cell Receptor On-Target Specificity via Structure-Guided Design. Mol Ther 2019;27:300-13.

68. Madura F, Rizkallah PJ, Legut M, et al. TCR-induced alteration of primary MHC peptide anchor residue. Eur J Immunol 2019;49:1052-66.

69. Coles CH, Mulvaney RM, Malla S, et al. TCRs with Distinct Specificity Profiles Use Different Binding Modes to Engage an Identical Peptide-HLA Complex. J Immunol 2020;204:1943-53.

70. Wu LC, Tuot DS, Lyons DS, et al. Two-step binding mechanism for $\mathrm{T}$-cell receptor recognition of peptide MHC. Nature 2002;418:552-6.

71. Zhang H, Lim HS, Knapp B, et al. The contribution of major histocompatibility complex contacts to the affinity and kinetics of $T$ cell receptor binding. Sci Rep 2016;6:35326.

72. Blevins SJ, Pierce BG, Singh NK, et al. How structural adaptability exists alongside HLA-A2 bias in the human $\alpha \beta$ TCR repertoire. Proc Natl Acad Sci U S A 2016;113:E1276-85.

73. Yu K, Shi J, Lu D, et al. Comparative analysis of CDR3 regions in paired human $\alpha \beta$ CD8 T cells. FEBS Open Bio 2019;9:1450-9.

74. Aptsiauri N, Cabrera T, Mendez R, et al. Role of altered expression of HLA class I molecules in cancer progression. Adv Exp Med Biol 2007;601:123-31.

75. Darabi A, Thuring C, Paulsson KM. HLA-I antigen presentation and tapasin influence immune responses against malignant brain tumors - considerations for successful immunotherapy. Anticancer Agents Med Chem 2014;14:1094-100.

76. del Campo AB, Carretero J, Aptsiauri N, et al. Targeting HLA class I expression to increase tumor immunogenicity. Tissue Antigens 2012;79:147-54.

77. Coles CH, McMurran C, Lloyd A, et al. T cell receptor interactions with human leukocyte antigen govern indirect peptide selectivity for the cancer testis antigen MAGE-A4. J Biol Chem 2020;295:11486-94.

78. Tripathi SK, Salunke DM. Exploring the different states 
of wild-type T-cell receptor and mutant conformational changes towards understanding the antigen recognition. J Biomol Struct Dyn 2021;39:188-201.

79. Goyarts EC, Vegh Z, Kalergis AM, et al. Point mutations in the beta chain CDR3 can alter the $\mathrm{T}$ cell receptor recognition pattern on an MHC class I/peptide complex over a broad interface area. Mol Immunol 1998;35:593-607.

80. Wang QJ, Hanada K, Feldman SA, et al. Development of a genetically-modified novel $\mathrm{T}$-cell receptor for adoptive cell transfer against renal cell carcinoma. J Immunol Methods 2011;366:43-51.

Cite this article as: Zhu Y, Huang C, Su M, Ge Z, Gao L, Shi Y, Wang X, Chen J. Characterization of amino acid residues of T-cell receptors interacting with HLA-A*02-restricted antigen peptides. Ann Transl Med 2021;9(6):495. doi: 10.21037/atm-21-835
81. Wang F, Ono T, Kalergis AM, et al. On defining the rules for interactions between the $\mathrm{T}$ cell receptor and its ligand: a critical role for a specific amino acid residue of the T cell receptor beta chain. Proc Natl Acad Sci U S A 1998;95:5217-22.

82. Zhang $\mathrm{W}$, Honda $\mathrm{S}$, Wang $\mathrm{F}$, et al. Immunobiological analysis of TCR single-chain transgenic mice reveals new possibilities for interaction between CDR3alpha and an antigenic peptide bound to MHC class I. J Immunol 2001;167:4396-404. 